\title{
A silver enhanced, gold labelled, immunosorbent assay for detecting antibodies to rubella virus
}

N Patel, B F Rocks, M P Bailey

\begin{abstract}
A silver enhanced, gold labelled, immunosorbent assay (SEGLISA) for the detection of IgG antibodies to the rubella virus in human serum was developed. Pre-coated microtitre wells are used as the immobilised base of rubella antigens on to which any rubella antibodies from patient samples will bind. This antigen/antibody complex is then visualised firstly by gold labelled anti-immunoglobulin $G$, which binds to any human IgG that may be present, and then by silver amplification, resulting in a black permanent deposit on the microtitre well surface. Patient samples ( $\mathbf{n}=121)$ were screened using a commercially available enzyme linked immunosorbent assay (ELISA) and an equivalent SEGLISA. Results were comparable but the SEGLISA does not have the disadvantages associated with enzyme labels. The silver deposit may also be read visually or the dried plate may be stored for future reference.
\end{abstract}

Progress has been made in the prevention of congenital rubella infections largely due to campaigns to increase rubella vaccinations in schoolgirls and women. Simple inexpensive screening tests are desirable to identify women at risk and to detect active infections with rubella virus, especially during the early antenatal period. ${ }^{1}$

There are currently several laboratory methods for the detection of rubella antibodies. ${ }^{23}$ Single radial haemolysis and haemagglutination inhibition tests are commonly used but these procedures are not easy to automate. Enzyme linked immunosorbent assay (ELISA), ${ }^{45}$ based tests may, where appropriate, be mechanised to facilitate high volume screening.

A new type of non-isotopic, non-enzymatic immunoassay, called a silver enhanced gold labelled immunosorbent assay (SEGLISA), has recently been reported. ${ }^{6}$ In this paper we describe further developments of this technique and its applicability to the detection of rubella antibodies. It was our aim to devise a high volume screening test, using commercially available consumables and reagents that could, if necessary, be visually interpreted. The use of this experimental test was compared with an established commercially available ELISA.

The principle of the test comprised the following: microtitre wells precoated with inactivated rubella are used as the immobilised antigen phase; these bind any rubella antibodies in the serum. The rubella antibody/antigen complex is then visualised using an anti-human $\mathrm{IgG}$ molecule conjugated with $5 \mathrm{~nm}$ gold particles. This gold conjugate binds to any rubella IgG antibodies that may be present producing a faint red stain.

Further visualisation occurs with silver amplification. This entails reduction of a silver compound by a reducing agent to produce silver ions, which precipitate around the gold particles. A positive test results in a silver deposit coating the surface of the well, the intensity of staining depending on the amount of rubella antibodies present. The amount of light blocked by the thin silver layer can be quantified by "apparent absorbance" measurement of the microtitre wells.

\section{Methods}

A commercially available kit (Captia RubellaG) from Mercia Diagnostics Ltd, Guildford, was used for the ELISA tests and coated plates from this kit were also used for the SEGLISA. Antihuman IgG gold conjugate (Auroprobe $\mathrm{LM} \mathrm{GaHu)} \mathrm{was} \mathrm{supplied} \mathrm{by} \mathrm{Janssen} \mathrm{Life}$ Sciences, Olen, Belgium (5 nm gold particle size). Silver enhancer solutions were supplied by Janssen Life Sciences (IntenSE $M$ ) and Sigma Chemical Co, Poole (SE-100). The gold conjugates and silver enhancement reagents are normally used as detection aids for use with electron and light microscopy techniques.

Although enhancing solutions from both Janssen and Sigma gave adequate results, we found that a more intense deposit of silver was obtained by adding hydroquinone and gum acacia, supplied by BDH, Poole, to the Sigma reagents. All other chemicals and reagents, unless stated, were supplied by Sigma. Storage of reagents was at $4^{\circ} \mathrm{C}$.

As a high proportion of the general population have been exposed to rubella, either naturally acquired or as a result of vaccination, antibody positive and negative samples were obtained by randomly collecting specimens that had been sent to the laboratory for biochemical analysis. It was noted whether the blood samples were from men or women before numbering and storing the separated sera at $-20^{\circ} \mathrm{C}$.

Standard laboratory microtitre equipment was used. Absorbances of microtitre wells were read at $450 \mathrm{~nm}$ using a microplate reader (Dynatech MR 250; Billingshurst). 
Table 1 Test panel results by ELISA and SEGLISA (Figures in parentheses show percentage of group)

\begin{tabular}{lcclllll}
\hline & ELISA & \multicolumn{5}{l}{ SEGLISA } \\
\cline { 2 - 3 } & Positive & Negative & Equivocal & & Positive & Negative & Equivocal \\
\hline Men & $35(68 \cdot 6)$ & $15(29 \cdot 4)$ & $1(2)$ & & $36(71)$ & $15(29)$ & $0(0)$ \\
Women & $65(92 \cdot 9)$ & $5(7 \cdot 1)$ & $0(0)$ & & $66(94)$ & $4(6)$ & $0(0)$ \\
Total & $100(82 \cdot 6)$ & $20(16 \cdot 5)$ & $1(0 \cdot 83)$ & & $102(84 \cdot 3)$ & $19(15 \cdot 7)$ & $0(0)$ \\
\hline
\end{tabular}

ASSAY PROCEDURE

Test sera and ELISA kit controls were diluted 1 in 100 with buffer diluent $(8 \mathrm{~g} \mathrm{NaCl}, 0.2 \mathrm{~g}$ $\mathrm{KH}_{2} \mathrm{PO}_{4}, \quad 2.9 \mathrm{~g} \quad \mathrm{NaH}_{2} \mathrm{PO}_{4} .12 \mathrm{H}_{2} \mathrm{O}+1 \%$ bovine serum albumin $+0.05 \%$ Tween 20 made up to 1 litre using deionised water, $\mathrm{pH} \mathrm{7.4)}$ and $100 \mu \mathrm{l}$ of each was added to polystyrene microtitre wells precoated with inactivated rubella antigens and incubated at $37^{\circ} \mathrm{C}$ for 60 minutes.

The diluted serum was then aspirated and the wells washed three times in wash buffer $(8 \mathrm{~g}$ $\mathrm{NaCl}, 0.2 \mathrm{~g} \mathrm{KH}_{2} \mathrm{PO}_{4}, 2.9 \mathrm{~g} \mathrm{NaH}_{2} \mathrm{PO}_{4} .12 \mathrm{H}_{2} \mathrm{O}$ $+0.05 \%$ Tween 20 made up to 1 litre using deionised water, $\mathrm{pH}$ 7.4). The antibody/ antigen complex was then detected by either an ELISA or a SEGLISA.

\section{SEGLISA}

IgG gold conjugate $(100 \mu \mathrm{l})$ (diluted 1 in 50 with buffer diluent) was added to each of the wells and incubated at $37^{\circ} \mathrm{C}$ for 60 minutes. The wells were then washed three times with wash buffer and $100 \mu \mathrm{l}$ of modified Sigma SE-100 silver enhancement solution (equal volumes of initiator $A$ and enhancer $B$ solutions $+0.5 \%$ hydroquinone $+0.05 \%$ Gum acacia) was added and left for 20 minutes at room temperature.

After washing three times with distilled water the wells were visually interpreted and absorbances of the wells measured at $450 \mathrm{~nm}$. It was not necessary to fix the silver deposit.

When viewed against a white background the SEGLISA wells were particularly easy to read visually. The plates could be read with wash solution in them or drained and read dry.
Table 2 Precision of SEGLISA and ELISA

\begin{tabular}{lll}
\hline & SEGLISA & ELISA \\
\hline n & 16 & 16 \\
Mean A & 0.932 & 1.230 \\
SD $(\%)$ & 0.079 & 0.073 \\
CV & 6.2 & 5.9 \\
\hline
\end{tabular}

$\mathrm{n}$ is the number of times the assay was repeated, $\mathrm{A}$ is the absorbance, $\mathrm{SD}$ is the standard deviation and $\mathrm{CV}$ is its coefficient of variation.

\section{ELISA}

Anti-human IgG-horse-radish peroxidase conjugate solution $(100 \mu \mathrm{l})$ (diluted 1 in 200 with buffer diluent) was added to each well and incubated at $37^{\circ} \mathrm{C}$ for 60 minutes. The excess conjugate was aspirated and the wells washed three times in wash buffer.

The substrate was made up 10 minutes before use by diluting tetramethylbenzidine chromogen (TMB) in dimethyl sulfoxide 1 in 100 with substrate solution (citrate acetate buffer $\left.+\mathrm{H}_{2} \mathrm{O}_{2}\right)$. Substrate $(100 \mu \mathrm{l})$ was added to each well and incubated at room temperature for 30 minutes after which time $25 \mu \mathrm{l}$ of $2 \mathrm{M}$ $\mathrm{H}_{2} \mathrm{SO}_{4}$ was added to stop the reaction. After mixing, the wells were visually interpreted and read at $450 \mathrm{~nm}$.

All tests were carried out in duplicate and the results quoted as the mean absorbance. The antibody titre was expressed as its sample/ reference $(S / R)$ index, which is the absorbance of test/absorbance of low titre positive (LTP), where the LTP is the cut-off value for this ELISA kit. The $S / R$ of the LTP is therefore 1 , an $S / R$ of less than 1 is negative, an $S / R$ of
Figure 1 Histogram showing number and category of samples corresponding to different sample/reference indices after an ELISA and a SEGLISA on 121 patient samples. Negative patient samples are shown on the left of the chart with positives on the right. The extreme right bar interval shows all results with a ratio greater than 3 .

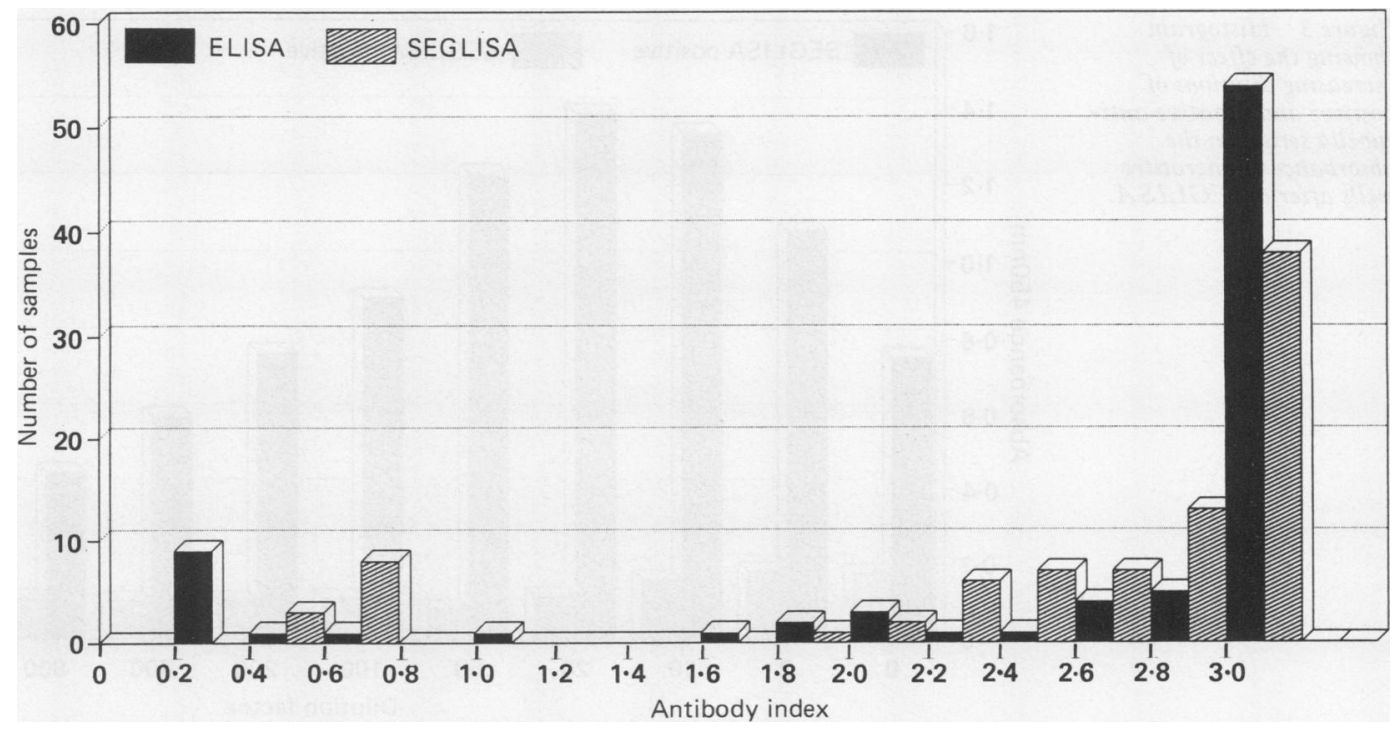


Figure 2 Histogram showing the effect of increasing dilutions of positive and negative antirubella serum on the absorbance of microtitre wells after an ELISA.

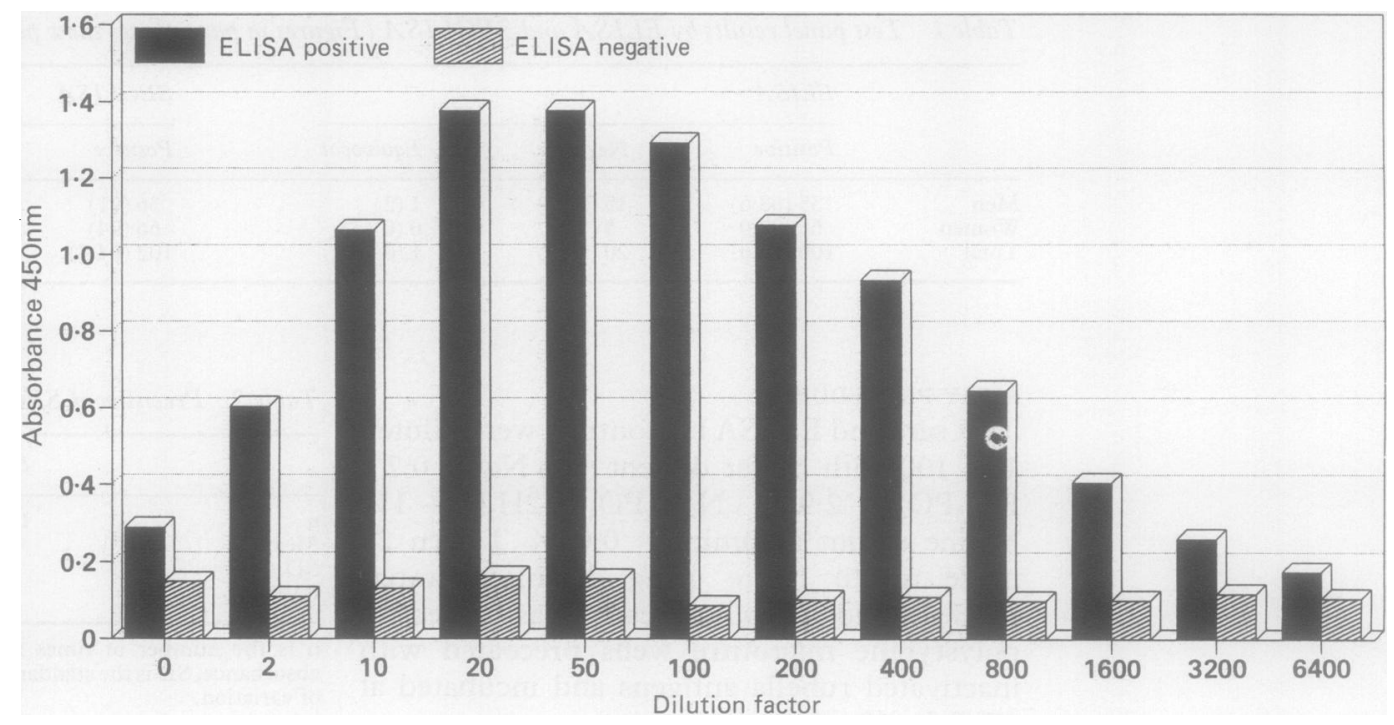

greater than 1 is positive, and an $S / R$ between 0.9 and 1.1 is equivocal (test repeated).

\section{Results}

A panel of 121 sera was screened for the presence of rubella antibodies using an ELISA and a SEGLISA as described. Controls of high titre positive (HTP), low titre positive (LTP), and negative titre (Mercia Diagnostics Ltd) were used, with the LTP being designated as the cut off standard for positive and negative results.

The antibody response for the test panel and for the men and women by both tests is shown in table 1. A histogram of the samples in terms of $S / R$ index is given in fig 1 . Two distinct groups were seen representing positive and negative samples.

Positive sera for the ELISA showed a mean $S / R$ index of 3.5, whereas for the SEGLISA it was 3.0. Negative sera fell into a group with a mean S/R index of 0.47 for the ELISA and 0.67 for the SEGLISA. Kit controls were correctly identified with the HTP, giving a positive $S / R$ index of 2.02 and $2 \cdot 20$, and the negative control showing negative values of 0.26 and 0.55 for the ELISA and SEGLISA, respectively.

In general there was good agreement for individual sera (for indices, between 0 and 3 , $r=0.94)$. Two samples, however $(1.65 \%)$ showed differing results between the two assays. One was equivocal for the ELISA $(S / R=1)$ but showed a positive result for the SEGLISA $(S / R=1.9)$ and one was negative for the ELISA ( $/ R=0.72$ ) with a positive result for the SEGLISA $(S / R=2 \cdot 1)$.

Retesting confirmed these results. Under such circumstances the retesting of a fresh serum sample would be desirable, but as these samples were selected from a panel of frozen sera, this was not possible.

The precision of the SEGLISA and the ELISA was compared by analysis of a positive rubella antibody sample. The results are shown in table 2.

The relative sensitivities of the assays to detect low concentrations of antibodies was compared by titrating diluted sera. Positive and negative serum samples were diluted 1 in 1,1 in 2,1 in 10,1 in 20,1 in 50,1 in 100,1 in 200,1 in 400,1 in 800,1 in 1600,1 in 3200 and 1 in 6400 .
Figure 3 Histogram showing the effect of increasing dilutions of positive and negative antirubella serum on the absorbance of microtitre wells after a SEGLISA.

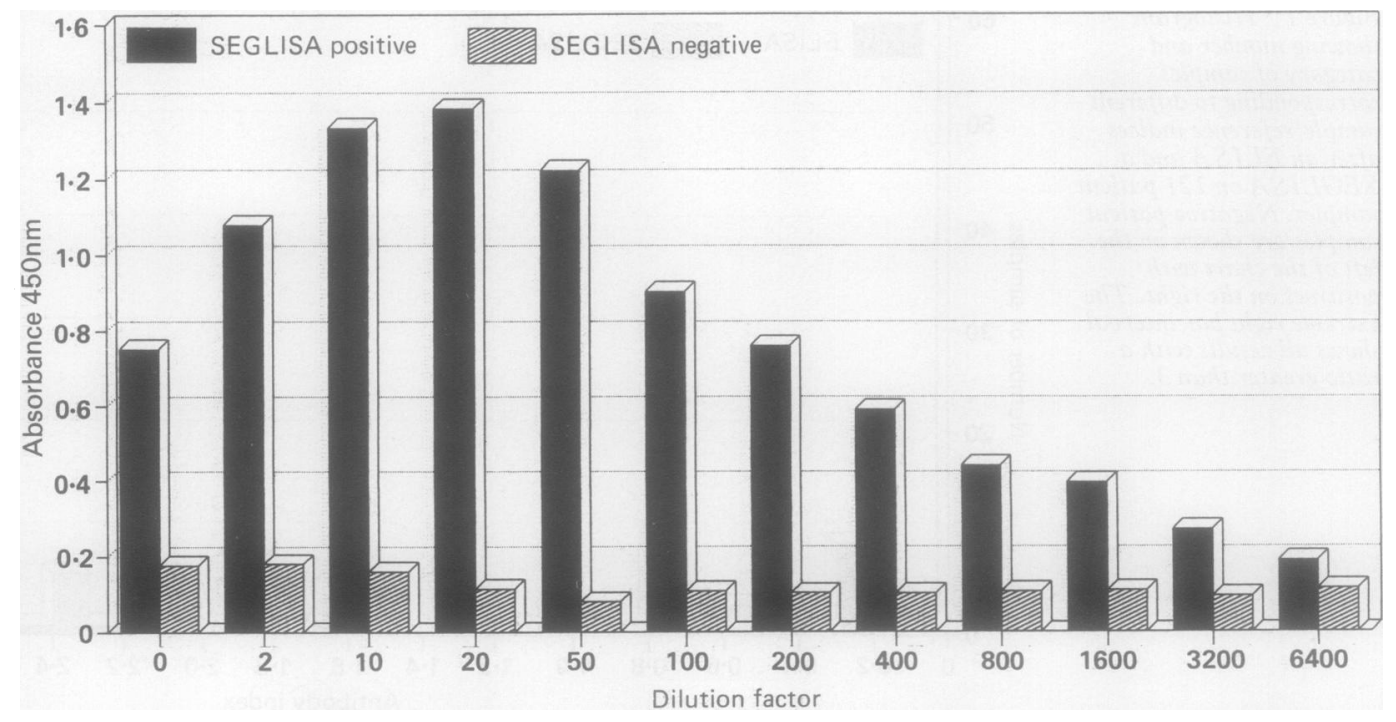


Figure 4 Photograph showing the appearance of a microtitre plate after a SEGLISA. Wells $H-1$, 2, 7 and 8 contained negative controls, wells $H-5,6,11$ and 12 contained high titre positive controls, and wells $\mathrm{H}-3,4,9,10$ the low titre positive controls which were used as the cutoff for negative and positive test results. All other wells contained patient samples which have been tested in duplicate.

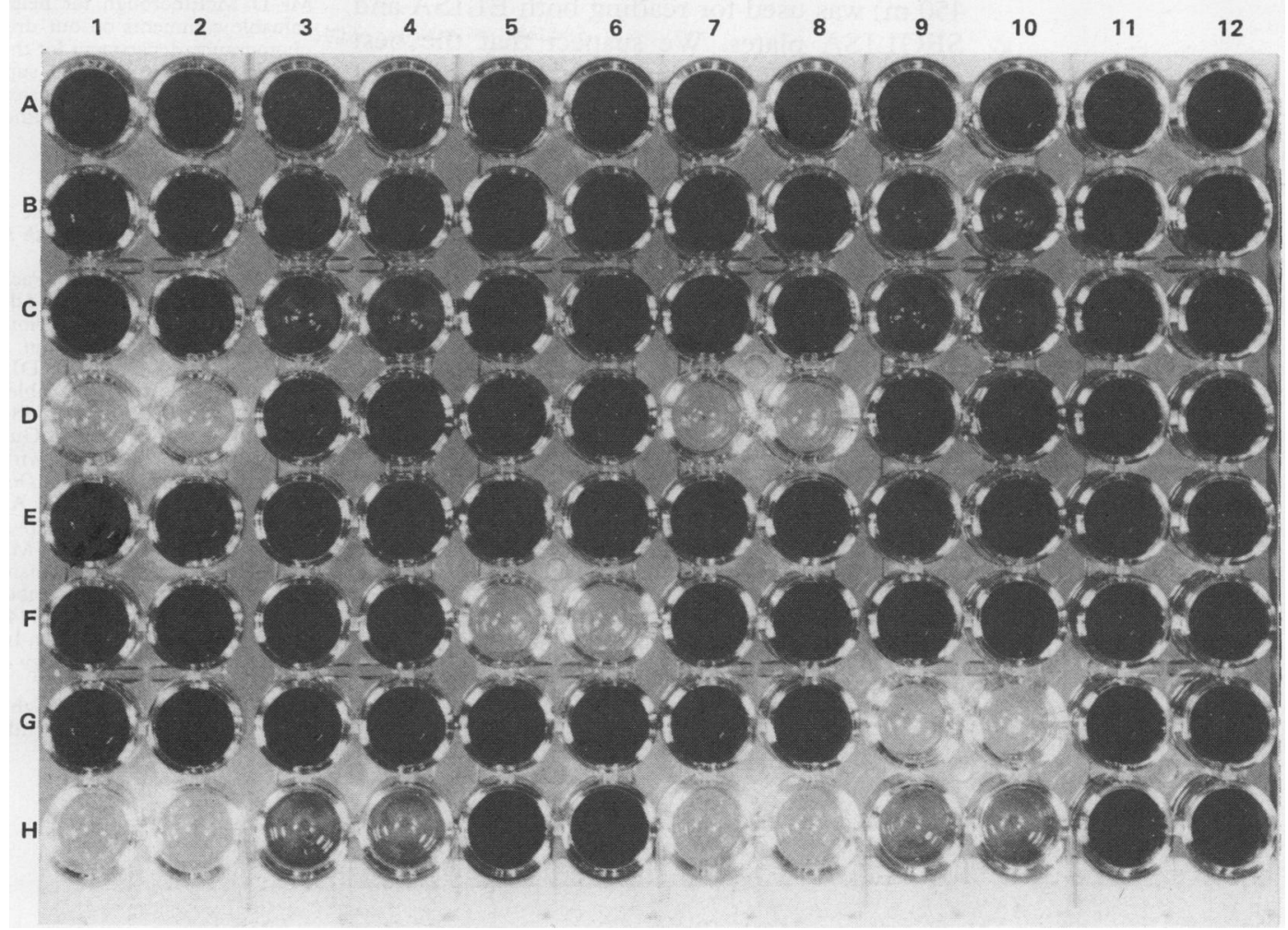

A SEGLISA and ELISA was then carried out on each dilution.

Both assays showed a positive result for all dilutions up to 1 in 6400 (fig 2 and 3), with negative results only when higher dilutions were used.

Negative serum dilutions gave negative values for both assays at all dilutions.

The cut-off control produced a thin silver layer on the well bottom which appeared light grey on visual inspection. All the patients' samples gave either no visible deposit, or a dense silver layer which appeared black by eye (fig 4). Consequently, it was easy to categorise SEGLISA wells as negative or positive by visual comparison with the cut-off control. There was complete agreement between assignment of the wells by visual inspection and the assignment based on $S / R$ ratios calculated from absorbances measured using the plate reader.

Visual categorisation of ELISA wells proved more difficult, particularly for those samples with an apparent colour intensity close to that of the cut-off control.

\section{Discussion}

From a methodological point of view SEGLISA is similar to the ELISA: the same technique and apparatus are used. Silver enhancement takes about 20 minutes compared with about 30 minutes for the enzyme reaction. The addition of acid to stop the enzyme and the subsequent mixing also add to the time required to carry out an ELISA.

Visual interpretation of the SEGLISA was particularly easy. Wells containing no antibody remained clear while most positive results produced a distinct black layer of silver on the bottom and sides of the wells. Low positive results produced a less dense layer, grey in colour, which was easy to compare with the control. Although negative and strong positive samples were also visually distinguishable using the ELISA, we found it difficult to relate the faint yellow solution of low positive results and some negative results to the similarly coloured cut-off control. The colorimetric plate reader, however, had no such difficulty and to our surprise could better discriminate between samples assayed by the ELISA than by the SEGLISA. For most samples, however, the separation between positive and negative samples was excellent by both assays. Because the silver deposit is permanent, drained and dried SEGLISA plates can be stored for reading at a different time or place. Dried plates showed no deterioration after one year's storage at room temperature.

In terms of precision and detection limit the SEGLISA compares well with the ELISA and there was good agreement on the assignment of antibody titre to the sera comprising the test panel. The percentage of antibody positive subjects and the number of women who remained susceptible to infection fall within ranges reported from other population studies. ${ }^{78}$ The discrepancy rate $(1.65 \%)$ is lower than that found by other authors who have compared methods for detecting rubella antibodies. ${ }^{25}$ The discrepant results probably arise from the differing specificities of the labelled anti-human IgGs used to detect the rubella antibodies.

Because of the black to grey colour resulting with positive sera we assumed that when reading the SEGLISA plates by colorimeter that the wavelength was not important. Consequently, the same plate reader filter $(\lambda=$ 
$450 \mathrm{~m}$ ) was used for reading both ELISA and SEGLISA plates. We suspect that the best results would be obtained without the use of any filter, but this was not possible with our plate reader. To read optimally the thin silver layer on the bottom of the well, different optics may be more appropriate.

Compared with other established methods for detecting antibodies to rubella ELISAs require no pretreatment of the sera, and are well suited to mechanisation; consequently, in recent years their use has been on the increase. The SEGLISA approach offers all the advantages of ELISAs but as it does not involve an enzyme incubation stage it requires fewer manipulations and is quicker to carry out. The SEGLISA reagents are at least as stable as those used in ELISAs and their cost is comparable. A major advantage of SEGLISA is that visual interpretation is easy and a permanent record of the result is obtained.

We thank Jane Seacombe for the gift of the Mercia ELISA kits,
Mr D McElborough for helpful advice, Dr JGH Cook for valuable comments on our draft manuscript and the medical photography department for the photograph of our plate.

We acknowledge financial support from the Department of Health (Procurement Division) and from the South East Thames Regional Health Authority.

1 Morgan-Capner P. The detection of Rubella-specific antibody. Public Health Laboratory Service Microbiology Digest 1983;1:6-11.

2 Enders G, Knotek F, Pacher U. Comparison of various serological methods and diagnostic kits for the detection of acute, recent and previous rubella infection, vaccination and congenital infection. $J$ Med Virol 1985;16:219-32.

3 Castellano GA, Madden DL, Hazzard GT, et al. Evaluation of commercially available diagnostic test kits for rubella. of commercially available diagn

4 Gravell M, Dorsett PH, Gutenson O, Ley AC. Detection of antibodies to rubella virus by enzyme-linked immunosorbent assay. J Infect Dis 1977;136:S300-3

5 Voller A, Bidwell DE. A simple method for detecting antibodies to rubella. Br J Exp Pathol 1975;56:338-9.

6 Rocks BF, Bertram VMR, Bailey MP. Detection of antibodies to the human immunodeficiency virus by silver-enhanced gold-labelled immunosorbent assay. Ann Clin Biochem 1990;27:114-20.

7 Horstmaan DM. Rubella. In: Evans AS, ed. Viral infections of humans. Epidemiology and control. New York: J Wiley and Sons, 1978:409-27.

8 Miller CL, Miller E, Waight PA. Rubella susceptability and the continuing risk of infection in pregnancy. Br Med J the continuing rist

\section{Eponyms in pathology ...}

YERSIN, Alexandre Emil-Jean (18631943) was a Swiss microbiologist. Born near Lausanne and trained in Paris, he qualified in 1888. He was one of Pasteur's distinguished pupils, and with Emile Roux, in 1888, was the first to demonstrate diphtheria toxin. In 1894 he became a medical officer in the French colonial army and served in Indo-China. Independently of Kitasato he discovered the plague bacillus in Hong Kong in 1894; an organism now known as Yersinia pestis. In 1896 he developed an anti-plague serum with Calmette and did much to control epidemics in Indo-China. He became director of the Pasteur institute at Nha-Trang in Annam (now Vietnam). 